\title{
Avaliação de parâmetros cinéticos de quitinases produzidas por Beauveria bassiana (Bals.) Vuill.
}

\author{
Evaluation of kinetic parameters of chitinases produced by \\ Beauveria bassiana (Bals.) Vuill.
}

\author{
Danieli Cristina Sassá1; Geni Varéa-Pereira ${ }^{2 *}$; Dalva Tomoe Miyagui ${ }^{2}$; \\ Pedro Manoel de Oliveira Janeiro Neves ${ }^{3}$; Jo I Wu; \\ Vanessa Hitomi Sugahara; Cristiane Mita; Evelyn Kamogawa
}

\section{Resumo}

\begin{abstract}
Beauveria bassiana é um fungo entomopatogênico utilizado no controle biológico de insetos-praga que infestam produtos agrícolas. O mecanismo de infecção envolve a produção de enzimas extracelulares, como proteases e quitinases que degradam a cutícula dos insetos. O objetivo deste trabalho foi avaliar parâmetros cinéticos de $\mathrm{pH}$, temperatura, concentração iônica e tempo de reação sobre a atividade de quitinases. O fungo B. bassiana CG432 foi repicado em broca do café Hypothenemus hampei (Ferrari) e utilizado para preparar o inóculo contendo $10^{8}$ conídios ativados $/ \mathrm{mL}$. Estes conídios foram inoculados $1 \%(\mathrm{v} / \mathrm{v})$ em meio de cultura líquido constituído por D-glicose (10g), extrato de levedura $(5 \mathrm{~g}), \mathrm{NaNO}_{3}$ $(1,58 \mathrm{~g}), \mathrm{Na}_{2} \mathrm{HPO}_{4} \cdot 7 \mathrm{H}_{2} \mathrm{O}(1,05 \mathrm{~g}), \mathrm{KCl}(1 \mathrm{~g}), \mathrm{MgSO}_{4} \cdot 7 \mathrm{H}_{2} \mathrm{O}(0,6 \mathrm{~g})$ e $\mathrm{KH}_{2} \mathrm{PO}_{4}(0,36 \mathrm{~g})$ por litro. $\mathrm{O}$ cultivo foi conduzido a $28^{\circ} \mathrm{C}$ e $180 \mathrm{rpm}$ durante 5 dias. O fluido extracelular do cultivo foi obtido por filtração e centrifugação a $8.000 \mathrm{~g}$, e as quitinases foram isoladas e concentradas por ultrafiltração entre membranas de 10 e $100 \mathrm{kDa}$ sob pressão de nitrogênio. A atividade das quitinases foi determinada pela quantificação da $\mathrm{N}$-acetilglicosamina liberada pela hidrólise da quitina coloidal durante 60 minutos de incubação a temperaturas de 40 a $60^{\circ} \mathrm{C}$, concentrações iônicas dos tampões acetato de sódio $\mathrm{pH} 4,0$ a 6,0 ; fosfato de sódio pH 6,0 a 8,0; e glicina- $\mathrm{NaOH} \mathrm{pH} \mathrm{8,0} \mathrm{a} \mathrm{10,0,} \mathrm{a} \mathrm{50,} 100$ e $200 \mathrm{mM}$. A atividade das quitinases foi máxima a $45^{\circ} \mathrm{C}$, em pH 5,5, mas também foi elevada em $\mathrm{pH}$ 6,0 e 8,5 em concentração iônica de $50 \mathrm{mM}$. A atividade de quitinases aumentou durante uma hora de incubação demonstrando estabilidade das enzimas nas condições ótimas da reação.
\end{abstract}

Palavras-chave: Fungos entomopatogênicos; Biocontrole; Hypothenemus hampei.

\footnotetext{
Abstract

Entomopathogenic fungus Beauveria bassiana is currently used as a biocontrol agent for agricultural pests. The infection process involves extracellular enzymes such as proteases and chitinases that degrade the cuticle of the insects. The objective of this work was to evaluate kinetic parameters of $\mathrm{pH}$, temperature, ionic concentration and time of reaction on chitinases activity. The fungus B. bassiana CG432 was cultivated on coffee berry borer Hypothenemus hampei (Ferrari) and the conidia grown on insect were used to prepare the inoculum containing $10^{8} \mathrm{conídia} / \mathrm{mL}$. These conidia were inoculated at $1 \%(\mathrm{v} / \mathrm{v})$ in

1 Programa de Pós-Graduação em Biotecnologia/CCE/Universidade Estadual de Londrina

2 Departamento de Bioquímica e Biotecnologia/CCE/Universidade Estadual de Londrina

Campus Universitário, Caixa Postal 6001, CEP 86081-990, Londrina-Pr, Brasil, fone (43) 33714270, e-mail gpvarea@uel.br

3 Departamento de Agronomia/CCA/Universidade Estadual de Londrina

Suporte financeiro: CAPES, CNPq, Fundação Araucária/Pr
}

* Autor para correspondência 
culture liquid medium containing D-glucose $(10 \mathrm{~g})$, yeast extract $(5 \mathrm{~g}), \mathrm{NaNO}_{3}(1,58 \mathrm{~g}), \mathrm{Na}_{2} \mathrm{HPO}_{4} \cdot 7 \mathrm{H}_{2} \mathrm{O}$ $(1,05 \mathrm{~g}), \mathrm{KCl}(1 \mathrm{~g}), \mathrm{MgSO}_{4} \cdot 7 \mathrm{H}_{2} \mathrm{O}(0,6 \mathrm{~g})$ and $\mathrm{KH}_{2} \mathrm{PO}_{4}(0,36 \mathrm{~g})$ per liter. The cultivation was carried at $28^{\circ} \mathrm{C}$ and $180 \mathrm{rpm}$ during 5 days. Culture fluid was obtained by filtration and centrifugation at $8.000 \mathrm{~g}$, and the chitinases were isolated and concentrated by ultrafiltration using 10 and $100 \mathrm{kDa}$ cut off membranes under nitrogen pressure. Chitinase activity was detected and quantified using $\mathrm{N}$-acetylglucosamine released by hydrolysis of colloidal chitin at 40 to $60^{\circ} \mathrm{C}$, at 50,100 and $200 \mathrm{mM}$ ionic concentrations of buffers sodium acetate ( $\mathrm{pH} 4.0$ to 6.0); sodium phosphate ( $\mathrm{pH} 6.0$ to 8.0); and Glycine- $\mathrm{NaOH}$ ( $\mathrm{pH} 8.0$ to 10.0 ) during 60 minutes. Maximum chitinase activity was at $45^{\circ} \mathrm{C}$ and $\mathrm{pH} 5.5$, and was also high at $\mathrm{pH} 6.0$ and $\mathrm{pH} 8.5$ using $50 \mathrm{mM}$ buffer. The chitinase activity increased and was stable during an hour at optimum conditions of the reaction, shown the stable nature of this enzyme.

Key words: Entomopathogenic fungus, Biocontrol, Hypothenemus hampei.

\section{Introdução}

Fungos entomopatogênicos têm sido utilizados como alternativa ao controle de insetos-praga na agricultura com o objetivo de reduzir o uso de inseticidas químicos. Estes fungos apresentam vantagens, em relação a outros agentes microbianos do controle biológico, porque não necessitam ser ingeridos para causar doença nos insetos (ALVES, 1998). A infecção ocorre por adesão dos conídios fúngicos, e subsequente penetração da cutícula protetora dos insetos devido à produção de enzimas extracelulares e pressão mecânica exercida pelas estruturas de reprodução dos conídios (KHACHATOURIANS, 1996).

Proteases e quitinases têm sido aceitas como os principais fatores determinantes da virulência dos fungos entomopatogênicos (St. LEGER et al., 1986b), pois hidrolisam os principais polímeros constituintes da cutícula, proteínas e quitina, organizados em camadas denominadas exo e endocutícula.

A quitina consiste de uma cadeia de poli- $\beta$ $1,4-\mathrm{N}$-acetilglicosamina e representa em torno de 25-40\% da cutícula do inseto (COHEN-KUPIEC; CHET, 1998). As cadeias adjacentes de quitina estão interligadas por pontes de hidrogênio formando microfibrilas que ficam embebidas e unidas, através de ligações cruzadas, com moléculas de proteínas que perfazem cerca de $70 \%$ da cutícula (CHAPMAN, 1998).

Cultivos dos fungos entomopatogênicos Metarhizium anisopliae (Metsh) Sorokin, Beauveria bassiana (Bals.) Vuill e Aspergillus flavus Link: Fr demonstraram a produção de múltiplas isoformas de quitinases extracelulares, caracteristicamente resistentes à ação proteolítica, regulada por mecanismos de indução-repressão exercidos pela quitina e seus produtos de degradação no meio cultivo (St. LEGER et al., 1993).

Imagens de microscopia eletrônica da cutícula de larvas de Manduca sexta L. tratadas com anticorpo anti-quitinases e infectadas pelos fungos entomopatogênicos $M$. anisopliae, $M$. flavoride Gams \& Rosypal e B. bassiana, revelaram aumento significativo da atividade de quitinases em regiões internas da cutícula, coincidentes com locais previamente degradadas por proteases, sugerindo a ação complementar destas enzimas na solubilização da cutícula e penetração do fungo (St LEGER et al., 1996).

B. bassiana cepa CG432 isolada de insetos mortos Hemiptera: Membracidae na região nordeste do Brasil, demonstrou elevado crescimento sobre adultos de broca do café Hypothenemus hampei (Ferrari) (NEVES; HIROSE, 2005), e rápida produção de proteases extracelulares em apenas 2 dias de cultivo inoculado com suspensão de conídios previamente ativados em seu hospedeiro (ITO et al, 2007), sendo este tempo de produção de proteases, muito inferior aos publicados por cultivos de B. Bassiana realizados em meio enriquecidos com substratos protéicos como gelatina e caseína (URTZ; RICE, 2000) ou com cutícula moída de gafanhoto (St LEGER et al., 1986a). 
Stürmer, et al. (2005) demonstraram que proteases, precocemente produzidas, por inóculo de $B$. bassiana previamente ativados em insetos, apresentaram atividade em $\mathrm{pH}$ alcalino 9,5 como outras proteases descritas anteriormente (BIDOCHKA; KHACHATOURIANS, 1987), mas se caracterizaram também por apresentar atividade em pH ácido 4,5, sugerindo a ativação de múltiplas formas da enzima.

Considerando as evidências de que a infecção de fungos entomopatogênicos resulta da ação sinérgica e complementar entre enzimas extracelulares; que ocorre indução destas enzimas pelo contato com o hospedeiro; e que o estudo dos mecanismos de ação das enzimas colabora com informações sobre a ação bioinseticida dos fungos entomopatogênicos, o presente trabalho estudou alguns parâmetros cinéticos da atividade das quitinases produzidas por B. bassiana CG432 após ativação em insetos vivos de broca do café.

\section{Material e Métodos}

\section{Ativação do inóculo}

Beauveria bassiana CG432, proveniente do Banco de Entomopatógenos do Departamento de Agronomia da Universidade Estadual de Londrina, foi inicialmente repicado em meio de cultura sólido constituído por D-glucose anidra $(10 \mathrm{~g})$, extrato de levedura (5g), $\mathrm{NaNO}_{3}(1,58 \mathrm{~g}), \mathrm{Na}_{2} \mathrm{HPO}_{4} \cdot 7 \mathrm{H}_{2} \mathrm{O}$ $(1,05 \mathrm{~g}), \mathrm{KCl}(1 \mathrm{~g}), \mathrm{MgSO}_{4} \cdot 7 \mathrm{H}_{2} \mathrm{O}(0,6 \mathrm{~g}), \mathrm{KH}_{2} \mathrm{PO}_{4}$ $(0,36 \mathrm{~g})$, ágar $(20 \mathrm{~g})$ e estreptomicina $(0,5 \mathrm{~g})$ por litro de água destilada, e incubado em câmara climatizada $\mathrm{BOD}$ a $25^{\circ} \mathrm{C}, 12 \mathrm{~h}$ fotofase durante 10 dias. A seguir, uma suspensão dos conídios obtida foi utilizada para imergir adultos vivos de brocado-café (Hypothenemus hampei) conforme descrito por Neves; Hirose (2005). Após a morte do inseto, os conídios recém-emergidos do inseto morto, "conídios ativados", foram novamente repicados, no máximo três vezes, em meio de cultura sólido. A incubação foi realizada nas mesmas condições anteriormente descritas, até obtenção de número suficiente de conídios ativados para preparo do inóculo dos cultivos submersos de produção das quitinases.

\section{Produção e isolamento das quitinases}

Foram realizados cultivos submersos da cepa de $B$. bassiana $\mathrm{CG} 432$ a $28^{\circ} \mathrm{C}, 150 \mathrm{rpm}$ através da inoculação de $1 \%$ de uma suspensão contendo $10^{8}$ conídios/mL recém-ativados em broca-do-café utilizando meio de cultura líquido com a mesma composição do meio sólido, porém sem adição de ágar e preparado conforme descrito por Ito et al. (2007), porém aumentando a relação espaço aéreo/ meio de cultivo para $1 / 5$. Todos os cultivos foram realizados em triplicata. Paralelamente, foram realizados outros dois cultivos controle utilizando inóculo sem prévia ativação em broca do café e sem adição de inóculo.

Após cinco dias de cultivo, o fluido extracelular (FEC) foi separado da biomassa por filtração a vácuo e centrifugação a $4^{\circ} \mathrm{C}$ a $8.000 \mathrm{~g}$ durante 20 minutos.

A separação das quitinases foi realizada por tratamento do FEC centrifugado através de diálise exaustiva contra tampão acetato $5 \mathrm{mM}$ pH 5,0 a $4^{\circ} \mathrm{C}$ durante 24 horas, seguida por duas etapas de ultrafiltração (UF) sob pressão de nitrogênio (Stirred cell-Sigma): a primeira, em membrana de porosidade controlada, para separação da maioria das moléculas contaminantes maiores que $100 \mathrm{kDa}$; e a segunda, em membrana de porosidade controlada, tanto para separação de moléculas menores que $10 \mathrm{kDa}$, como para redução do volume do FEC e conseqüente concentração das quitinases. Finalmente, o FEC concentrado foi congelado e utilizado como fonte de enzima para determinação das características de atividade das quitinases extracelulares.

\section{Preparo do substrato quitina coloidal}

$20 \mathrm{~g}$ de quitina da carapaça de caranguejo em pó (Practical Grade, Sigma) foi digerida em $200 \mathrm{~mL}$ de 
$\mathrm{HCl}$ concentrado, precipitada como quitina coloidal em água gelada e enxaguada por filtração até $\mathrm{pH}$ 5,5 (KANG et al., 1999). A umidade final da quitina coloidal foi padronizada a $90 \%$ por gravimetria a $70^{\circ} \mathrm{C}$ e armazenada sob congelamento.

\section{Determinação da atividade das quitinases}

A atividade das quitinases foi determinada por adaptações da técnica de Nahar et al (2004). Alíquotas de $0,5 \mathrm{~mL}$ do FEC obtidos nas diferentes etapas de separação das quitinases foram incubadas com $1 \mathrm{~mL}$ de quitina coloidal preparada a $1 \%$ em de tampão acetato $100 \mathrm{mM} \mathrm{pH} \mathrm{5,0} \mathrm{a} \mathrm{50} \mathrm{C.} \mathrm{Após} 1$ hora, a reação enzimática foi interrompida em banhomaria fervente por 1 minuto. A quitina residual foi separada por centrifugação a $2000 \mathrm{~g}$ por 15 minutos e o sobrenadante usado para a determinação da concentração de $\mathrm{N}$-acetilglicosamina produzida pela ação enzimática empregando o método descrito por Reissig et al. (1955). Uma unidade de atividade enzimática foi definida como $\mu \mathrm{g}$ de $\mathrm{N}$-acetilglicosamina liberados por $\mathrm{mL}$ da solução da enzima nas condições da reação.

\section{Efeito das condições de reação sobre a atividade} das quitinases

Avaliou-se o efeito do $\mathrm{pH}$, concentração iônica, temperatura e tempo de reação sobre atividade das quitinases somente em alíquotas do FEC concentrado por ultrafiltração em membrana de porosidade controlada $10 \mathrm{kDa}$ utilizando a técnica descrita acima, porém com modificações necessárias para cada teste. As análises foram realizadas em três repetições

\subsection{Efeito do pH e concentração iônica}

$\mathrm{O}$ efeito do $\mathrm{pH}$ e concentração iônica do meio de reação sobre a atividade das quitinases foi avaliado utilizando temperatura de incubação de $50^{\circ} \mathrm{C}$ e quitina coloidal a $1 \%$ preparada nas concentrações
50,100 e $200 \mathrm{mM}$ dos tampões acetato de $\mathrm{pH} 4,0$ a 6,0; fosfato de $\mathrm{pH} 6,0$ a 8,0; e glicina- $\mathrm{NaOH}$ de $\mathrm{pH}$ 8,0 a 10,0. A determinação da atividade de quitinases foi realizada em intervalos de 0,5 unidades de $\mathrm{pH}$.

\subsection{Efeito da temperatura}

O efeito da temperatura da reação sobre atividade das quitinases foi avaliado utilizando quitina coloidal a $1 \%$ preparada em soluções a $50 \mathrm{mM}$ dos tampões acetato $\mathrm{pH} 5,5$, fosfato $\mathrm{pH} 6,0$ e glicina- $\mathrm{NaOH} \mathrm{pH}$ 8,5 nas temperaturas de incubação de 40 a $60^{\circ} \mathrm{C}$. A determinação da atividade de quitinases foi medida em intervalos de $5^{\circ} \mathrm{C}$.

\subsection{Efeito do tempo de reação}

O efeito do tempo de reação sobre atividade das quitinases foi avaliado por incubação com quitina coloidal $1 \%$ preparada em soluções a $50 \mathrm{mM}$ dos tampões acetato $\mathrm{pH} 5,5$, fosfato $\mathrm{pH}$ 6,0 e tampão glicina- $\mathrm{NaOH} \mathrm{pH} 8,5$ a $45^{\circ} \mathrm{C}$ durante 1 hora. A determinação da atividade das quitinases foi realizada em intervalos de 15 minutos de incubação.

\section{Resultados e Discussão}

\section{Isolamento das quitinases}

Considerando que as quitinases extracelulares produzidas por fungos apresentam massas moleculares em torno de 60kDa (FANG et al., 2005) e os dados apresentados na Tabela 1, observase que a ultrafiltração sob condições controladas de pressão e porosidade de membranas (100 e 10 kDa), resultou em ótimos resultados de isolamento das quitinases, pois separou e concentrou em apenas $20 \mathrm{~mL}$, as proteínas com atividade de quitinase com 93\% de rendimento e elevada atividade específica sobre o substrato quitina igual a 71.000, sendo, portanto 14,6 vezes superior ao FEC dialisado inicial (5.184). 
Tabela 1. Tratamento do fluido extracelular (FEC) com atividade de quitinases produzidas em cultivo submerso por Beauveria bassiana CG432

\begin{tabular}{cccccc}
\hline Etapa & $\begin{array}{c}\text { Volume } \\
(\mathrm{mL})\end{array}$ & $\begin{array}{c}\text { Proteína } \\
(\mathrm{mg})\end{array}$ & $\begin{array}{c}\text { Atividade de } \\
\text { quitinases } \\
(\mathrm{U}) *\end{array}$ & $\begin{array}{c}\text { Atividade específica } \\
\text { de quitinases } \\
(\mathrm{U} / \mathrm{mg} \text { de proteínas })\end{array}$ & $\begin{array}{c}\text { Rendimento } \\
\text { da atividade de } \\
\text { quitinases }(\%)\end{array}$ \\
\hline $\begin{array}{c}\text { FEC } \\
\text { dialisado }\end{array}$ & 2.200 & 206 & 1.068 .000 & 5.184 & 100 \\
$\begin{array}{c}\text { FEC ultrafiltrado } \\
(100 \mathrm{kDa})\end{array}$ & 8 & 100 & 35.000 & 350 & 3,3 \\
$\begin{array}{c}\text { FEC concentrado } \\
(10 \mathrm{kDa})\end{array}$ & 20 & 14 & 998.000 & 71.000 & 93 \\
\hline
\end{tabular}

* Unidades de quitinase: microgramas de N-acetilglucosamina liberadas por a ação da enzima sobre o substrato quitina. Incubação em tampão $10 \mathrm{mM}$ pH 5,0, 50 $\mathrm{C}$ durante 1 hora.

\section{Efeito do pH e concentração iônica}

Observou-se maior atividade das quitinases em tampões a $50 \mathrm{mM}$ de íons acetato $\mathrm{pH}$ 5,5 (Fig. 1A), fosfato $\mathrm{pH}$ 6,0 (Fig.2B) e glicina- $\mathrm{NaOH} \mathrm{pH} 8,5$ (Fig.2C).

Aconcentração de $50 \mathrm{mM}$ dos tampões promoveu, possivelmente, maior solubilização do substrato e condição de força iônica adequada para melhor rearranjo do sítio catalítico da enzima, pois o aumento da concentração dos íons constituintes dos tampões acetato e glicina- $\mathrm{NaOH}$ reduziu significativamente (Fig. 1A e 1C) e inativou totalmente a atividade das quitinases em tampão fosfato 200mM (Fig. 1B). Considerando que os fungos entomopatogênicos $M$. anisopliae, M. flavoviridae e B. bassiana produziram quitinases com valores de $\mathrm{pH}$ isoelétricos iguais a 4,8 e 7,5 (St LEGER et al., 1996), possivelmente, a predominância de cargas negativas na estrutura molecular das quitinases foram decisivas para interação com regiões positivas do substrato quitina coloidal nas condições ótimas de $\mathrm{pH} 5,5$, 6,0 e 8,5 observados neste trabalho. Desta forma, a elevada concentração iônica dos tampões mais concentrados a $200 \mathrm{mM}$, especialmente os íons fosfato, potencialmente com maior número de cargas negativas por mol, pode ter saturado os sítios de ligação promovendo a redução da interação enzimasubstrato através de mecanismo competitivo.

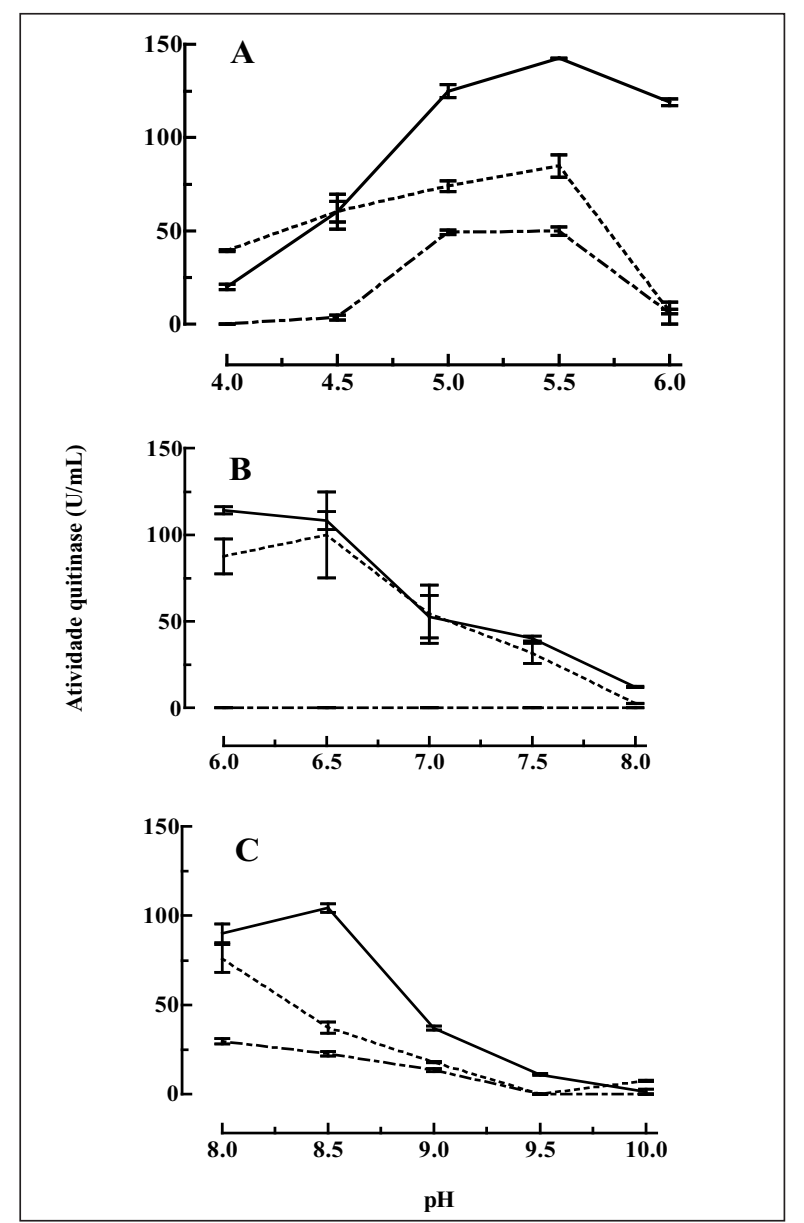

Figura 1. Efeito do $\mathrm{pH}$ e das concentrações $50 \mathrm{mM}(-)$, $100 \mathrm{mM}(\cdot \cdots \bullet \bullet)$ e $200 \mathrm{mM}(-\bullet-\bullet)$ dos tampões acetato de $\mathrm{pH} 4,0$ a 6,0 (A), fosfato de $\mathrm{pH} 6,0$ a 8,0 (B) e glicina$\mathrm{NaOH}$ de $\mathrm{pH} 8,0$ a $10,0(\mathrm{C})$ a $50^{\circ} \mathrm{C}$ sobre a atividade das quitinases do fluido extracelular concentrado obtido no quinto dia de cultivo de B. bassiana cepa CG432 previamente ativadas em de broca do café. Os resultados representam as médias das repetições. 
Dependendo do tipo de substrato presente no meio de cultura ou no ensaio enzimático, quitinases produzidas por fungos entomopatogênicos foram ativas em pH 5,0 (PINTO et al., 1997; NAHAR et al., 2004), e em pH alcalino (PEDRAZA-REYES; LOPEZ-ROMERO, 1989).Destaforma, asquitinases ativas nos valores de pH 5,5, 6,0 e 8,5 obtidas neste trabalho, sugere a produção de diferentes formas de quitinases extracelulares pelo fungo $B$. bassiana CG432. A multiplicidade das quitinases parece estar relacionada com a necessidade de produzir isoformas com atividade de quitina diacetilase, endo e exoquitinases para hidrolisar totalmente o polímero de quitina (NAHAR et al., 2004), e com modificações pós-transducionais, particularmente pela adição de diferentes tipos e porcentagens de moléculas de carboidratos na cadeia polipeptídica da quitinases (HARMAN et al., 1993).

\section{Efeito da temperatura}

A Figura 2 mostra que a temperatura máxima para atividade das quitinases ocorreu a $45^{\circ} \mathrm{C}$ em todos os valores ideais de $\mathrm{pH}$ e concentração iônica para cada tampão definidos neste trabalho, especialmente em pH 5,5. Sahai; Manocha (1993), em sua revisão sobre quitinases, observaram que a temperatura ótima de atividade de quitinases fúngicas pode variar de 38 a $50^{\circ} \mathrm{C}$ A elevação de temperatura de 50 a $60^{\circ} \mathrm{C}$ reduziu até $90 \%$ ou inativou as quitinases em todos os valores de $\mathrm{pH}$ testados.

\section{Efeito do tempo de reação}

A atividade das quitinases aumentou em função do tempo de reação, mais uma vez com predomínio da atividade em pH 5,5 (Fig. 3). Estes resultados demonstraram também que as quitinases foram estáveis durante os 60 minutos definidos como tempo de reação para determinar a atividade das quitinases estudadas neste trabalho. A elevada estabilidade de quitinases pode estar relacionada com o grau de glicosilação da molécula (SAHAI; MANOCHA, 1993).

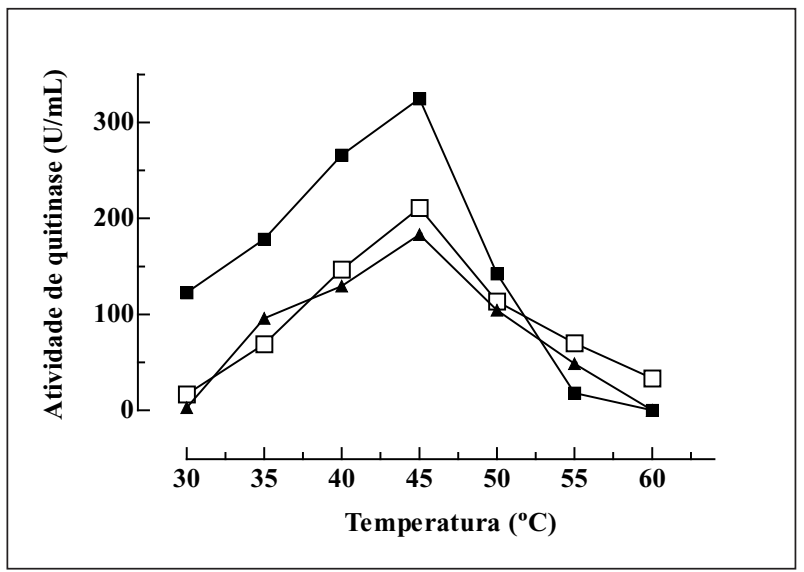

Figura 2. Efeito da temperatura sobre a atividade das quitinases do fluido extracelular concentrado obtidos no quinto dia de cultivo de B. bassiana cepa CG432 previamente ativadas em de broca do café nos tampões

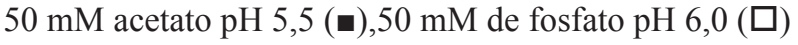
e $50 \mathrm{mM}$ de glicina- $\mathrm{NaOH}$ pH 8,5 ( $\Delta$ ). Os resultados representam as médias das repetições.

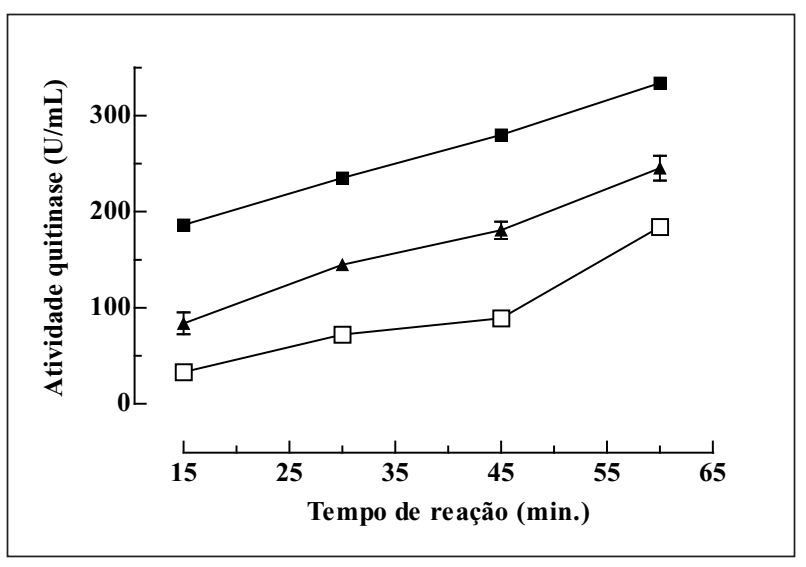

Figura 3. Efeito do tempo de reação sobre a atividade de quitinases do fluido extracxelular do cultivo de $B$. bassiana cepa CG432 a $45^{\circ} \mathrm{C}$ nos tampões acetato 50 $\mathrm{mM}$ pH 5,5 (घ), fosfato $50 \mathrm{mM} \mathrm{pH} \mathrm{6,0( \square )} \mathrm{e} \mathrm{glicina}$

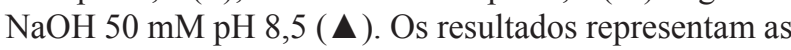
médias das repetições.

\section{Conclusão}

Beauveria bassiana cepa CG432 previamente ativadas em adultos vivos de broca do café produziu quitinases extracelulares com atividade enzimática máxima a $45^{\circ} \mathrm{C}$ predominantemente em tampão acetato $50 \mathrm{mM}$ pH 5,5, pH 6,0 e glicina- $\mathrm{NaOH}$ pH 8,5 . Nestas condições de reação as quitinases foram estáveis por uma hora. 


\section{Agradecimentos}

Os autores agradecem a Fundação Araucária e CNPq pela concessão da bolsa de mestrado e recursos para realização da pesquisa, e ao técnico Nelson Janeiro Rodriguez pelo auxílio nos trabalhos laboratoriais.

\section{Referências Bibliográficas}

ALVES, S. B. Controle Microbiano de Insetos. 2.ed. Piracicaba:FEALQ, 1998, 1163p.

BIDOCHKA, M.; KHACHATOURIANS, G. Purification and properties of an extracelullar protease produced by the entomopathogenic fungus Beauveria bassiana. Applied Environmental Microbiology, v. 53, p. 16791684, 1987.

CHAPMAN, R.J. Integument. In: The insects: structure and function. $4^{\text {th }}$ ed. Cambridge University Press, 1998. p.415-440.

COHEN-KUPIEC, R.; CHET, I. The molecular biology of chitin digestion. Current Opinion in Biotechnology, v.9, p.270-277, 1998.

FANG, W.; LENG.; B.; XIAO, Y.; JIN, K.; M.A., J.; FAN, Y.; FENG, J.; YANG, X.; ZHANG, Y.; PEI, Y. Cloning of Beauveria bassiana chitinase gene Bbchit1 and its application to improve fungal strain virulence. Applied end Environmental Microbiology, v.71, n.1, p.363-370, 2005.

HARMAN, G. E.; HAYES, C. K.; LORITA M.; BRODWAY, R. M.; Di PIETRO, A.; PETERBAUER, C.; TRONSMO, A. Chitinolytic enzymes of Trichoderma harzianum: purification of chitobiosidade and endochitinase. Phytopathology, v. 83, p. 313-317, 1993.

ITO, E. T.; VARÉA-PEREIRA, G.; MIYAGUI, D. T.; PINOTTI, M. H. P.; NEVES, P. M. O. J. Production of extracellular proteases by a Brazilian strain of Beauveria bassiana reactivated on coffee berry borer, Hypothenemus hampei. Brazilian Archives of Biology and Technology, v. 50, n. 2, p. 217-223, 2007.

KANG, S. C.; PARK, S.; LEE, D. G. Purification and characterization of a novel chitinase from the entomopathogenic fungus Metarhizium anisopliae. Journal of Invertebrate Pathology, v.73, p.276-281, 1999.
KHACHATOURIANS, G. G. Biochemistry and molecular biology of entomopathogenic fungi. In__: The Mycota VI: Human and Animal Relationships. Howard/ Miller (Eds.). Sringer-Verlag Berlin Heidelberg, 1996.

NAHAR, P.; GHORMADE, V.; DESHPANDE, M. $\mathrm{V}$. The extracellular constitutive production of chitin deacetylase in Metarhizium anisopliae: possible edge to entomopathogenic fungi in the biological control of insect pests. Journal of Invertebrate Pathology, v.85, p.80-88, 2004.

NEVES, P. M. O. J.; HIROSE, E. Seleção de isolados de Beauveria bassiana para o controle biológico da brocado-café, Hypothenemus hampei (Ferrari) (Coleopetera: Scolytidae). Neotropical Entomology, v.34, n.1, p.77-82, 2005.

PEDROZA-REYES, M.; LOPEZ-ROMERO, E. Purification and some properties of two forms of chitinase from mycelial cells of Mucor rouxii. Journal General Microbiololgy, v. 135, p. 211-218, 1989.

PINTO, A. S.; BARRETO, C. B.; SCHRANK, A; ULHOA, C. J.; VAINSTEIN, M. H. Purification of na extracellular chitinase from the entomopathogen Metharhizium anisopliae. Canadian Journal of Microbiology, v. 43, p.322-327, 1997.

REISSIG, J. L.; STROMINGER, J. L.; LELOIS, L. F. A modified colorimetric method for the estimation of $\mathrm{N}$-acetylaminosugar. Journal of Biological Chemistry, v.217, n.2, p.959-966, 1955.

SAHAI, A. S.; MANOCHA, M. S. Chitinases of fungi and plants: their involvement in morphogenesis and hostparasite interaction. FEMS Microbiology Reviews, v.11, p.317-338, 1993.

St .LEGER, R. .; CHARNLEY, A. K.; COOPER, R. M. Cuticle-degrading enzymes of entomopathogenic fungi: synthesis in culture on cuticle. Journal of Invertebrate Pathology, v.48, p.85-95, 1986a

St. LEGER, R. J.; COOPER, R. M.; CHARLEY, A. $\mathrm{K}$. Cuticle-degrading enzymes of entomopathogenic fungi: cuticle degradation in vitro by enzymes from entomopathogens. Journal of Invertebrate Pathology, v.47, p.167-177, 1986b.

St. LEGER, R. J.; JOSHI, L.; BIDOCHKA, M. J.; RIZZO, N. W.; ROBERTS, D.W. Characterization and ultrastructural localization of chitinases from Metarhizium anisopliae, M. Alavoviride and Beauveria bassiana during fungal invasion of host (Manduca sexta) cuticle. Applied and Environmental Microbiology, v.62, n.3, p.907-912, Mar. 1996. 
St. LEGER, R. J.; STAPLES, R. C.; ROBERTS, D. W. Entomopathogenic isolates of Metarhizium anisopliae, Beauveria bassiana, and Aspergillus flavus produce multiple extracellular chitinase isozymes. Journal of Invertebrate Pathology, v.61, p.81-84, 1993.

STÜRMER, A. T.; ITO, E. T.; VARÉA-PEREIRA, G.; MIYAGUI, D. T. Stability of proteases produced by the entomopathogenic fungus Beauveria bassiana. UNOPAR
- Ciências Biológicas e da Saúde. v. 5/6, n. 1, p. 85-88, out. 2003/2004.

URTZ, B. E.; RICE, W. C. Purification and characterization of a novel extracellular protease from Beauveria bassiana. Mycological Research, v.104, n.2, p.180-186, Feb. 2000. 